\title{
Contamination of Zinc in Sediments at River Mouths and Channel in Northern Kaohsiung Harbor, Taiwan
}

\author{
Cheng-Di Dong, Chih-Feng Chen, and Chiu-Wen Chen
}

\begin{abstract}
The distribution, enrichment, accumulation, and potential ecological risk of zinc $(\mathrm{Zn})$ in sediments at river mouths and channel of northern Kaohsiung Harbor, Taiwan were investigated. Sediment samples from 12 locations of northern Kaohsiung Harbor were collected and characterized for $\mathrm{Zn}$, aluminum, water content, organic matter, total nitrogen, total phosphorous, total grease and grain size. Results showed that the $\mathrm{Zn}$ concentrations varied from $75-2,537 \mathrm{mg} / \mathrm{kg}$ with an average of $590 \pm 677 \mathrm{mg} / \mathrm{kg}$. The spatial distribution of $\mathrm{Zn}$ reveals that the $\mathrm{Zn}$ concentration is relatively high in the river mouth region, and gradually diminishes toward the harbor entrance region. This indicates that upstream industrial and municipal wastewater discharges along the river bank are major sources of $\mathrm{Zn}$ pollution. Results from the enrichment factor analyses imply that the sediments collected from the river mouth can be characterized between severe and very severe degree enrichment of $\mathrm{Zn}$. However, results of potential ecological risk index indicate that the sediment has low ecological potential risk.
\end{abstract}

Index Terms-Accumulation, ecological risk, enrichment, sediment, zinc.

\section{INTRODUCTION}

Zinc $(\mathrm{Zn})$ is a very common environmental contaminant; its presence may be threatens the water ecological environment. Therefore, much research effort has been directed toward the distribution of $\mathrm{Zn}$ in water environment. Anthropogenic activities including municipal wastewater discharges, coal-burning power plants; manufacturing processes involving metals; and atmospheric fallout are the major source of $\mathrm{Zn}$ pollution [1]. Zn has low solubility in aqueous solution; it is easily adsorbed on water-borne suspended particles. After a series of natural processes, the water-borne $\mathrm{Zn}$ finally accumulates in the sediment, and the quantity of $\mathrm{Zn}$ contained in the sediment reflect the degree of pollution for the water body [2].

Kaohsiung Harbor is located on the southwestern shore, and it is the largest international harbor in Taiwan. However, it receiving effluents from four contaminated rivers, including Love River, Canon River, Jen-Gen River, and Salt River. Results of recent research indicate that the Kaohsiung Harbor is heavily polluted with $\mathrm{Zn}$, and the Love River and Canon River are both major pollution sources [2]. The two rivers flow through the downtown area of Kaohsiung City and finally discharged into Kaohsiung Harbor (Fig. 1). Love

Manuscript received August 23, 2012; revised November 27, 2012.

The authors are with Department of Marine Environmental Engineering, National Kaohsiung Marine University, Kaohsiung, Taiwan (e-mail: cddong@mail.nkmu.edu.tw; dong3762@mail.nkmu.edu.tw).
River and Canon River are located in Kaohsiung City's northern, basin area of about $45 \%$ of the entire Kaohsiung City, and regions along river have dense population with prosperous business and industrial establishments. The major pollution source includes domestic wastewater discharges, industrial wastewater discharges (e.g. paint and dye, chemical production, metal processing, electronic and foundry), municipal surface runoff, and transportation pollution [2]. All the pollutants will eventually be transported to the river mouth and/or harbor to deposit and accumulate in the bottom sediment.

The objective of this study is to investigate the $\mathrm{Zn}$ distribution in the surface sediment at river mouths and channel of northern Kaohsiung Harbor, Taiwan so that the degree of $\mathrm{Zn}$ enrichment, accumulation, and potential ecological risk can be evaluated.

\section{MATERIALS AND METHODS}

Twelve sampling stations were distributed in northern Kaohsiung Harbor, Taiwan (Fig. 1). Sediment samples were collected at 12 stations selected in this study in February, 2011 with Ekman Dredge Grab aboard a fishing boat. After transported back to the laboratory, a small portion of the sample was subject to direct water content analysis $(105 \mathrm{oC})$, and the remaining portion was preserved in $-20^{\circ} \mathrm{C}$ freezer to be analyzed later. Prior to being analyzed, each sample was lightly crushed with a wooden board, and then screened through $1 \mathrm{~mm}$ nylon net to remove particles with diameters larger than $1 \mathrm{~mm}$. One portion of the screened portion was

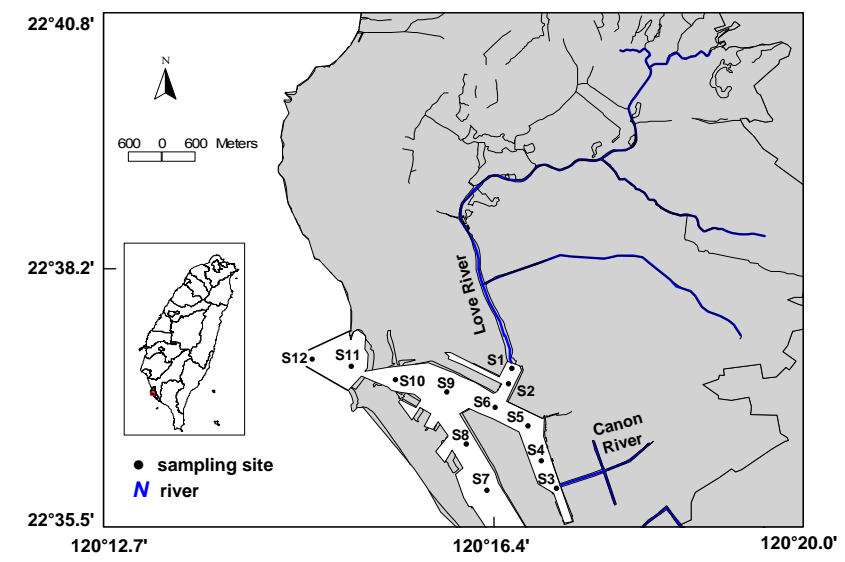

Fig. 1. Map of the study area and sampling locations.

subject to particle size analyses using a Coulter LS Particle Size Analyzer [2, 3]. Another portion was washed with ultra-pure water to remove sea salt; the salt-free particles were dried naturally in a dark place, grounded into fine powder with mortar and pestle made of agate, and then 
analyzed for organic matter (OM), total nitrogen (TN), total phosphorus (TP), total grease (TG), zinc ( $\mathrm{Zn})$, and aluminum (Al). For $\mathrm{Al}$ and $\mathrm{Zn}$ analyses, $0.5 \mathrm{~g}$ dry weight of the sediment sample was mixed with a mixture of ultra-pure acids $\left(\mathrm{HNO}_{3}: \mathrm{HCl}: \mathrm{HF}=5: 2: 5\right)$, and was then heated to digest. The digested sample was filtered through $0.45 \mu \mathrm{m}$ filter paper; the filtrate was diluted with ultra-pure water to a pre-selected final volume. The $\mathrm{Al}$ and $\mathrm{Zn}$ content were determined using a flame atomic absorption spectrophotometry (Hitachi Z-6100, Japan).

\section{RESUlTS AND DisCUSSION}

\section{A. Sediment Characteristics}

It has been reported that the distribution of particle size, $\mathrm{OM}, \mathrm{TN}, \mathrm{TP}$, and TG content were correlated to metal distribution in sediments [2]. Table I present the distribution of the major sediment characteristics in surface sediments at 12 monitoring stations studied. Results of sediment particle diameter analyses show that except Station S12, the major particles in sediment samples are silt $(2-63 \mu \mathrm{m})$ with a range
Clay contents were in the range of $0.8-19.9 \%$. Fine particles (dia. $<63 \mu \mathrm{m}$ ) that can easily adsorb and accumulate pollutants are the major component of particles found in the studied sediment. The water content, OM, TN, TP, and TG in the sediments from the study area have a similar spatial evolution characterized by the highest levels at Stations 1-4, which are located at the vicinity of the mouths of Love River, and Canon River. TN, TP, and TG were relatively high in the vicinity of the mouths of river compared with those at the harbor entrance areas (Station 12). The results show that the anthropogenic contribution from the harbor tributaries is the major source of TN, TP, and TG.

\section{B. Distribution of $\mathrm{Zn}$ in Sediments}

The contents of $\mathrm{Al}$ in the study sediments are between 4.18 and $5.29 \%$ with an average of $4.65 \pm 0.43 \%$ (Table I). All surface sediment samples collected at 12 monitoring stations studied contain $75-2,537 \mathrm{mg} / \mathrm{kg}$ of $\mathrm{Zn}$ with an average of $590 \pm 677 \mathrm{mg} / \mathrm{kg}$. Spatial distributions of Zn concentration in the surface sediment shown in Fig. 2 reveal that the sediment $\mathrm{Zn}$ content is relatively higher near the mouths of Love River,

\begin{tabular}{|c|c|c|c|c|c|c|c|c|c|c|}
\hline Station & $\begin{array}{c}\text { Clay } \\
(\%)\end{array}$ & $\begin{array}{l}\text { Silt } \\
(\%)\end{array}$ & $\begin{array}{c}\text { Sand } \\
(\%)\end{array}$ & $\begin{array}{c}\text { Water content } \\
(\%)\end{array}$ & $\begin{array}{l}\mathrm{OM} \\
(\%)\end{array}$ & $\begin{array}{c}\mathrm{TN} \\
(\mathrm{mg} / \mathrm{kg})\end{array}$ & $\begin{array}{c}\mathrm{TP} \\
(\mathrm{mg} / \mathrm{kg})\end{array}$ & $\begin{array}{c}\mathrm{TG} \\
(\mathrm{mg} / \mathrm{kg})\end{array}$ & $\begin{array}{c}\mathrm{Al} \\
(\%)\end{array}$ & $\begin{array}{c}\mathrm{Zn} \\
(\mathrm{mg} / \mathrm{kg})\end{array}$ \\
\hline $\mathrm{S} 1$ & 16.5 & 83.5 & 0.0 & 57.9 & 7.3 & 2665 & 655 & 1990 & 5.27 & 690 \\
\hline $\mathrm{S} 2$ & 17.8 & 82.2 & 0.0 & 113.2 & 6.0 & 2120 & 376 & 2284 & 5.29 & 808 \\
\hline $\mathrm{S} 3$ & 15.7 & 84.4 & 0.0 & 81.1 & 8.1 & 2762 & 736 & 1203 & 5.27 & 2537 \\
\hline S4 & 13.6 & 86.2 & 0.2 & 93.0 & 6.6 & 2000 & 514 & 960 & 4.50 & 1030 \\
\hline S5 & 14.5 & 84.9 & 0.6 & 86.7 & 3.7 & 1370 & 308 & 620 & 4.73 & 382 \\
\hline S6 & 18.0 & 82.0 & 0.0 & 91.2 & 4.9 & 1380 & 273 & 2440 & 4.40 & 386 \\
\hline S7 & 16.7 & 83.3 & 0.0 & 57.7 & 2.2 & 1089 & 213 & 410 & 4.40 & 216 \\
\hline S8 & 16.9 & 83.1 & 0.0 & 91.7 & 3.7 & 1103 & 261 & 1949 & 4.33 & 341 \\
\hline S9 & 14.3 & 85.2 & 0.5 & 86.1 & 4.0 & 1198 & 224 & 630 & 4.18 & 268 \\
\hline $\mathrm{S} 10$ & 13.9 & 84.9 & 1.1 & 42.1 & 2.8 & 1074 & 192 & 335 & 4.20 & 192 \\
\hline $\mathrm{S} 11$ & 19.9 & 80.1 & 0.0 & 58.9 & 3.9 & 1020 & 215 & 470 & 4.36 & 154 \\
\hline $\mathrm{S} 12$ & 0.8 & 6.3 & 92.9 & 28.6 & 3.4 & 875 & 294 & 305 & 4.84 & 75 \\
\hline Mean & 14.9 & 77.2 & 7.9 & 74.0 & 4.7 & 1555 & 355 & 1133 & 4.65 & 590 \\
\hline SD & 4.8 & 22.4 & 26.7 & 24.7 & 1.9 & 661 & 182 & 813 & 0.43 & 677 \\
\hline
\end{tabular}

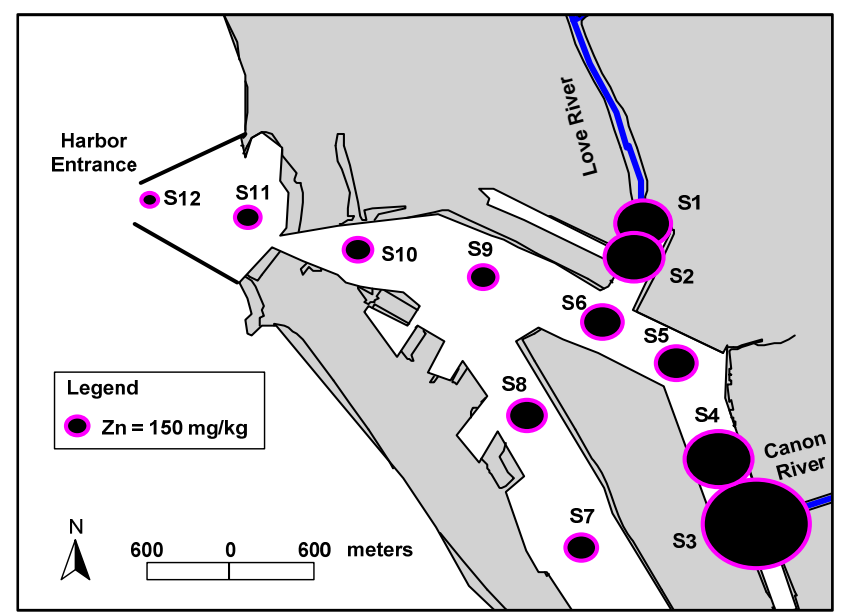

Fig. 2. Spatial distribution of $\mathrm{Zn}$ contents in surface sediment of northern Kaohsiung Harbor.

from $80.1 \%$ to $86.6 \%$. Station $\mathrm{S} 12$, located at the harbor entrance, had the highest sand contents $(92.9 \%)$ and the lowest silt contents (6.3\%); whereas Stations 1 and 11 had the highest silt contents and the lowest sand contents $(0.0-1.1 \%)$.

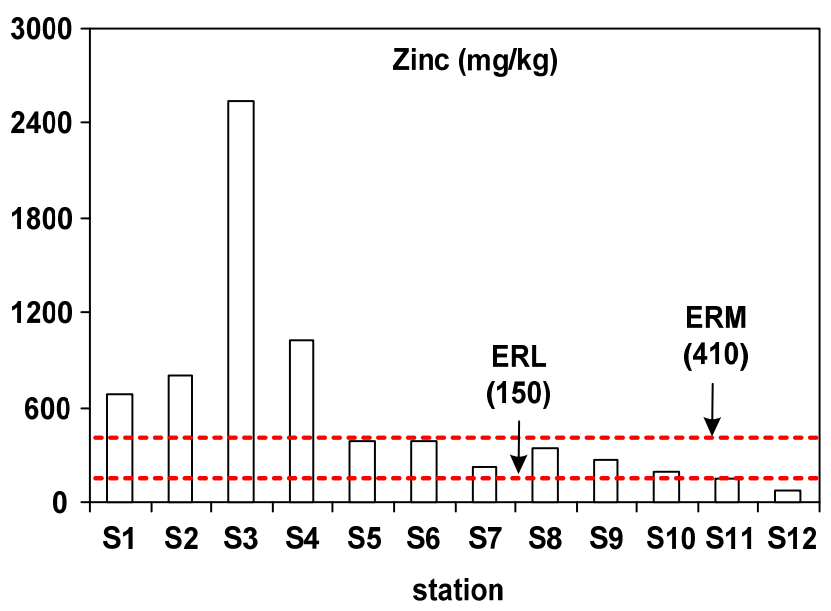

Fig. 3. Distribution of $\mathrm{Zn}$ contents in surface sediment of northern Kaohsiung Harbor.

and Canon River (Stations 1-4), and gradually decreases in the direction toward the mouth of harbor (Station 12). These observations clearly indicate that the upstream pollutants brought over by rivers are the major source of harbor $\mathrm{Zn}$ 
pollution. The two rivers receive a great amount of industrial and domestic $\mathrm{Zn}$ from Kaohsiung city because about $44 \%$ domestic wastewater is discharged directly without adequate treatment. Moreover, several industrial plants (e.g. metal processing, paint and dye, chemical manufacturing, electronic, motor vehicle plating and finishing, and foundries) discharge industrial wastewater effluents into the tributaries in or adjacent to Kaohsiung city, and the pollutants are transported by river flow and finally accumulate near the river mouth. Some pollutants may drift with sea current to be dispersed into open sea [2],[4].

Coefficient of the Pearson correlation between the sediment characteristics and $\mathrm{Zn}$ content is shown in Table II. The surface sediment $\mathrm{Zn}$ content is obviously correlated to OM content $(p<0.01)$ but not to particle size $(p>0.05)$ indicating that particle size are not major factors to control the $\mathrm{Zn}$ distribution. Although most studies presented significant negative correlation between sediment particle sizes and $\mathrm{Zn}$ concentrations [2],[5], results of this study indicated that OM contents were more important than grain size in controlling the distribution of $\mathrm{Zn}$ in the sediments. The results might suggest that the sorption mechanism of $\mathrm{Zn}$ at the study areas sediments is mainly controlled by chemical adsorption, rather than physical or deposition of $\mathrm{Zn}$ with OM on surface sediments [2]. It is noted that the $\mathrm{Zn}$ distribution in sediments were also significant positive correlation to $\mathrm{TN}$, and TP contents (Table II) which were usually derived from the upstream rivers with either industrial effluents or municipal sewage discharges.

\begin{tabular}{|c|c|c|c|c|c|c|c|c|c|}
\hline & clay & Silt & Sand & $\begin{array}{l}\text { Water } \\
\text { content }\end{array}$ & $\mathrm{OM}$ & $\mathrm{TN}$ & $\mathrm{TP}$ & TG & $\mathrm{Al}$ \\
\hline Silt & $0.889^{\mathrm{a}}$ & & & & & & & & \\
\hline Sand & $-0.924 a$ & $-0.997 \mathrm{a}$ & & & & & & & \\
\hline Water content & 0.545 & $0.581 \mathrm{~b}$ & $-0.583 b$ & & & & & & \\
\hline $\mathrm{OM}$ & 0.196 & 0.231 & -0.228 & 0.407 & & & & & \\
\hline $\mathrm{TN}$ & 0.154 & 0.210 & -0.202 & 0.185 & $0.922 \mathrm{a}$ & & & & \\
\hline $\mathrm{TP}$ & 0.048 & 0.203 & -0.177 & 0.081 & $0.845 \mathrm{a}$ & $0.882 \mathrm{a}$ & & & \\
\hline TG & 0.396 & 0.363 & -0.374 & $0.720 \mathrm{a}$ & 0.548 & 0.401 & 0.236 & & \\
\hline $\mathrm{Al}$ & -0.078 & -0.147 & 0.138 & 0.141 & $0.718 \mathrm{a}$ & $0.802 \mathrm{a}$ & 0.520 & 0.375 & \\
\hline $\mathrm{Zn}$ & 0.160 & 0.258 & -0.243 & 0.345 & $0.816 \mathrm{a}$ & $0.800 \mathrm{a}$ & $0.738 \mathrm{a}$ & 0.250 & $0.604 b$ \\
\hline
\end{tabular}

${ }^{a}$ Correlation is significant at the 0.01 level (2-tailed). ${ }^{\mathrm{b}}$ Correlation is significant at the 0.05 level (2-tailed).

\section{A. Comparison with Sediment Quality Guidelines}

Several numerical sediment quality guidelines have been developed for assessing the contamination levels and the biological significance of chemical pollutants recently [10, 11]. One of the widely used sediment toxicity screening guideline of the US National Oceanic and Atmospheric Administration provides two target values to estimate potential biological effects: effects range low (ERL) and effect range median (ERM) [11]. The guideline was developed by comparing various sediment toxicity responses of marine organisms or communities with observed metals concentrations in sediments. These two values delineate three concentration ranges for each particular chemical. When the concentration is below the ERL, it indicates that the biological effect is rare. If concentration equals to or greater than the ERL but below the ERM, it indicates that a biological effect would occur occasionally. Concentrations at or above the ERM indicate that a negative biological effect would frequently occur.

Fig. 3 shows the measured concentrations of $\mathrm{Zn}$ in comparison with the ERM and ERL values. Among the 12 sediment samples collected, the $\mathrm{Zn}$ is between ERL (150 $\mathrm{mg} / \mathrm{kg})$ and ERM $(410 \mathrm{mg} / \mathrm{kg})$ in 7 samples $(58.3 \%)$, and exceeds ERM in 4 samples (33.3\%). Only one sample collected from Station S12 is below ERL for Zn. This indicates that the concentration of $\mathrm{Zn}$ found in the study area sediments may cause adverse impact on aquatic lives. The study area is adjacent to the output of an industrial park that accommodates several chemical industrial plants using $\mathrm{Zn}$ compounds as raw materials. These plants are expected to release chemical pollutants which will accumulate in the bottom sediment of river mouth and harbor.

\section{B. Enrichment Factor}

The enrichment factor (EF) is a useful tool for differentiating the man-made and natural sources of metal contamination [5]. This evaluating technique is carried out by normalizing the metal concentration based on geological characteristics of sediment. Aluminum is a major metallic element found in the earth crust; its concentration is somewhat high in sediments and is not affected by man-made factors. Thus, Al has been widely used for normalizing the metal concentration in sediments $[2,5]$. EF is defined as: $E F$ $=(X / A l)_{\text {sediment }}(X / A l)_{\text {crust }}$, where $(X / A l)$ is the ratio of $\mathrm{Zn}$ to $\mathrm{Al}$. The average $\mathrm{Zn}$ and $\mathrm{Al}$ content in the earth crust were 70 $\mathrm{mg} / \mathrm{kg}$ and $8.23 \%$, respectively, which excerpted from the data published by Taylor (1964)[6]. When the EF of a metal is greater than 1 , the metal in the sediment originates from man-made activities, and vice versa. The EF value can be classified into 7 categories: 1 , no enrichment for $\mathrm{EF}<1$; , minor for $1<\mathrm{EF}<3$; 3, moderate for $3 \leq \mathrm{EF}<5$; 4 , moderately severe for $5 \leq \mathrm{EF}<10 ; 5$, severe for $10 \leq \mathrm{EF}<25$; 6 , very severe for $25 \leq \mathrm{EF}<50$; and 7 , extremely severe for $\mathrm{EF} \geq 50$. Table III(a) show EF values of the sediment $\mathrm{Zn}$ for 12 monitoring stations studied; the $\mathrm{Zn}$ concentration is consistent with the $\mathrm{Zn} \mathrm{EF}$ value for all sampling stations, and all EF values are greater than 1. This indicates that the sediment $\mathrm{Zn}$ has enrichment phenomenon with respect to the earth crust and that all $\mathrm{Zn}$ originates from man-made sources. 
Stations S1-S4 are classified between severe and extremely severe enrichment, Stations S5-S10 are classified as either moderately severe or severe enrichment, and Stations S11 and $\mathrm{S} 12$ are classified as moderate and minor enrichment, respectively. These results point out that the sediment near the mouth of rivers experiences severe enrichment of $\mathrm{Zn}$ that originates from the upstream sources of pollution.
Additionally, the EF value of 45.1 obtained in Station S3 (Canon River mouth) is higher than the EF value of 13.8 reported earlier [2] indicating that the upstream pollution has been continued to increase so that the accumulation of pollutants in sediments is more serious than that during earlier years.

TABLE III: EF, I $\mathrm{G}_{\mathrm{GFO}}$ AND PERI OF ZN FOR EACH STATION STUDIED AT NORTHERN KAOHSIUNG HARBOR

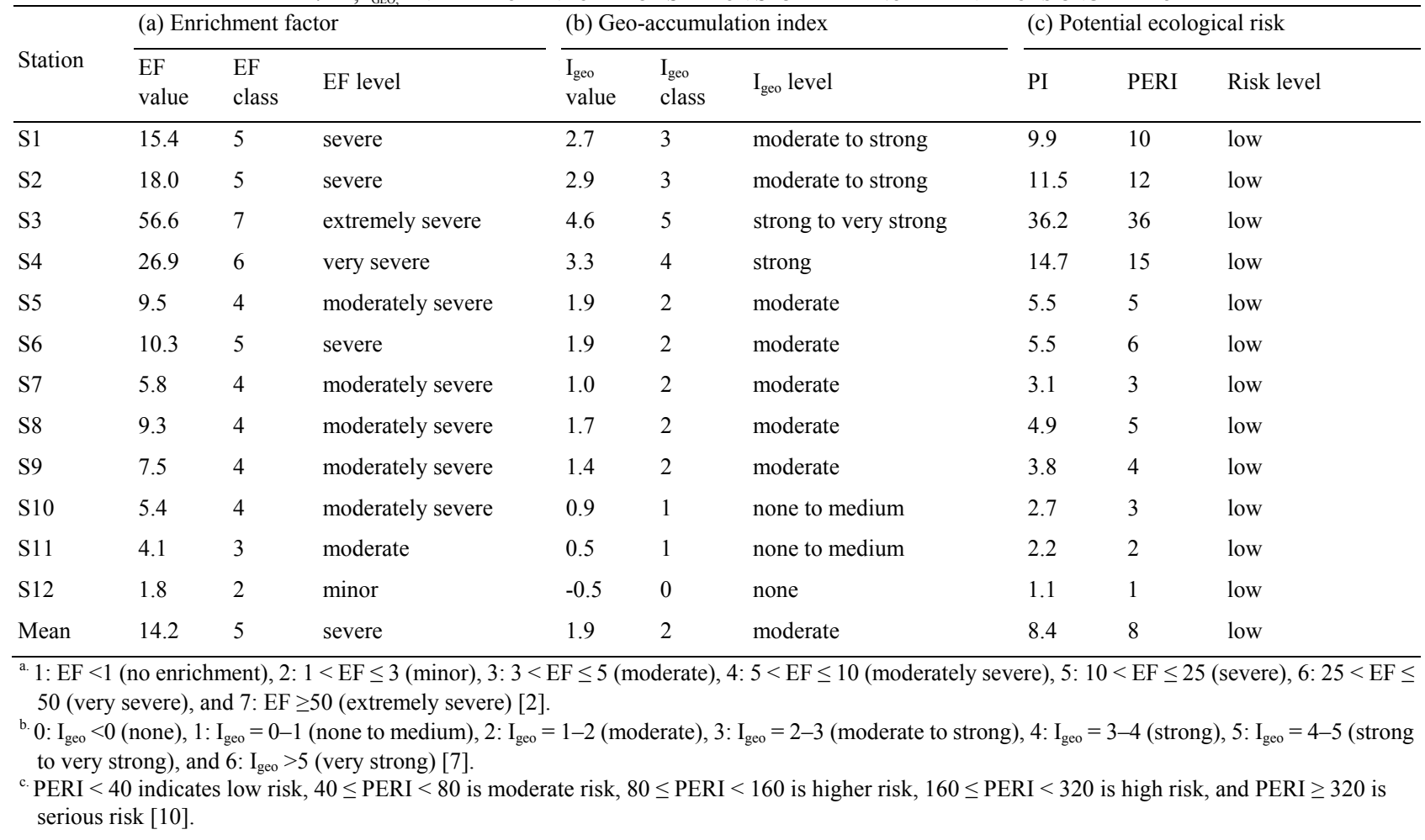

\section{A. Geo-Accumulation Index}

Similar to metal enrichment factor, geo-accumulation $\left(\mathrm{I}_{\mathrm{geo}}\right)$ index can be used as a reference to estimate the extent of metal accumulation. The Igeo values for the metals studied were calculated using the Muller's (1979) [7] expression: $I_{g e o}$ $=\log _{2}\left(C_{n} / 1.5 B_{n}\right)$, where $C_{n}$ is the measured content of element $\mathrm{Zn}$, and $\mathrm{B}_{\mathrm{n}}$ is the background content of $\mathrm{Zn} 70 \mathrm{mg} / \mathrm{kg}$ in the average shale. Factor 1.5 is the background matrix correction factor due to lithogenic effects. The $\mathrm{I}_{\text {geo }}$ value can be classified into 7 classes: 0 , none for $\mathrm{I}_{\mathrm{geo}}<0$; 1 , none to medium for $\mathrm{I}_{\text {geo }}=0-1 ; 2$, moderate for $\mathrm{I}_{\text {geo }}=1-2 ; 3$, moderately strong for $\mathrm{I}_{\text {geo }}=2-3 ; 4$, strong for $\mathrm{I}_{\text {geo }}=3-4 ; 5$, strong to very strong for $\mathrm{I}_{\mathrm{geo}}=4-5$; and 6 , very strong for $I_{\text {geo }}>5$. Based on the $I_{\text {geo }}$ data and geo-accumulation indexes, the accumulation levels with respect to $\mathrm{Zn}$ at each station are ranked in Table III(b). Stations S1-S4 are classified between moderately strong and strong to very strong accumulation, Stations S5-S9 are classified as moderate accumulation, and Stations S10-S12 are classified as either none to medium or none accumulation.

\section{B. Potential Ecological Risk}

The potential ecological risk index (PERI) is applied to evaluate the potential risk associated with the accumulation of $\mathrm{Zn}$ in surface sediments. PERI that was proposed by Hakanson (1980) [10] can be used to evaluate the potential risk of one metal or combination of multiple metals. The
PERI is defined as [10]: $P E R I=P I \times T_{i}$, where $P I$ (pollution index $)=\left(C_{i} / C_{f}\right) ; C_{i}$ is the measure concentration of $\mathrm{Zn}$ in sediment; $C_{f}$ is the background concentration of $\mathrm{Zn} ; T_{i}$ is its corresponding coefficient, i.e. 1 for $\mathrm{Zn}$ [11]. In this study, the average $\mathrm{Zn}$ concentration in earth crust of $70 \mathrm{mg} / \mathrm{kg}$ [6] was taken as the $\mathrm{Zn}$ background concentration. The calculated PERI values can be categorized into 5 classes of potential ecological risks $[10,11]$ : low risk $($ PERI $<40)$, moderate risk $(40 \leq$ PERI $<80)$, higher risk $(80 \leq$ PERI $<160)$, high risk $(160 \leq$ PERI $<320)$, and serious risk (PERI $\geq 320)$. Table III(c) lists the PI value, PERI value, and risk classification for the $\mathrm{Zn}$ contained in the surface sediment samples collected in this study. All stations are classified as low risk with respect to $\mathrm{Zn}$ pollution. The above evaluation results indicate that the $\mathrm{Zn}$ contained in surface sediments at the study area has low potential ecological risks. However, the PERI value near the river mouth of Stations S1-4 is higher than other sites (Table III(c)).

\section{CONCLUSIONS}

The surface sediment samples collected from the northern Kaohsiung Harbor contain 75-2,537 mg/kg of $\mathrm{Zn}$ with an average of $590 \pm 677 \mathrm{mg} / \mathrm{kg}$. The distribution of $\mathrm{Zn}$ in surface sediments reveals that the $\mathrm{Zn}$ originates from the river upstream discharges of industrial and domestic wastewaters; it is transported along the river and finally deposited and accumulated near the river mouth. Base on the comparison 
with SQGs, the concentrations of $\mathrm{Zn}$ in the mouths of Love River and Canon River sediments may cause acute biological damage. OM content is a more important factor than grain size in controlling the $\mathrm{Zn}$ distribution in the sediments. Results from the EF and $I_{\text {geo }}$ analyses imply that the sediments collected from the river mouth can be characterized between severe and extremely severe degree enrichment and between moderately strong and strong to very strong accumulation of $\mathrm{Zn}$, respectively. Compared to the EF values reported earlier [2], the degree of $\mathrm{Zn}$ enrichment at the river mouths has been obviously increased. Results of potential ecological risk evaluation show that the $\mathrm{Zn}$ contained in surface sediment at northern Kaohsiung Harbor has low potential ecological risks. The results can provide regulatory valuable information to be referenced for developing future strategies to renovate and manage river mouth and harbor.

\section{REFERENCES}

[1] E. Pertsemli and D. Voutsa, "Distribution of heavy metals in Lake Doirani and Kerkini, Northern Greece," Journal of Hazardous Materials, vol. 148, pp.529-37, 2007.

[2] C. W. Chen, C. M. Kao, C. F. Chen, and C. D. Dong, "Distribution and accumulation of heavy metals in the sediments of Kaohsiung Harbor, Taiwan," Chemosphere, vol.66, pp. 1431-1440, 2007.

[3] C. W. Chen, C. F. Chen, C. D. Dong, and Y. T. Tu, "Composition and source apportionment of PAHs in sediments at river mouths and channel in Kaohsiung Harbor, Taiwan," Journal of Environmental Monitoring, vol. 14, pp.105-115, 2012.

[4] C. W. Chen and C. F. Chen, "Distribution, origin and potential toxicological significance of polycyclic aromatic hydrocarbons (PAHs) in sediments of Kaohsiung Harbor, Taiwan," Marine Pollution Bulletin, vol. 63, pp. 417-423, 2011.

[5] K. M. Huang and S. Lin, "Consequences and implication of heavy metal spatial variations in sediments of the Keelung River drainage basin, Taiwan," Chemosphere, vol. 53, pp. 1113-1121, 2003.

[6] S. R. Taylor, "Abundance of chemical elements in the continental crust: a new table," Geochimica et Cosmochimica Acta, vol. 28, pp. 1273-1285, 1964.

[7] G. Müller, "Schwermetalle in den sediments des RheinsVeränderungen seit 1971," Umschan, vol.79, pp. 778-783, 1979.
[8] E. R. Long, D. D. MacDonald, S. L. Smith, and F. D. Calder, "Incidence of adverse biological effects within ranges of chemical concentrations in marine and estuarine sediments," Environmental Management, vol. 19, pp. 81-97, 1995.

[9] I. Riba, C. Casado-Martínez, J. M. Forja, and A. del Valls, "Sediment quality in the Atlantic Coast of Spain," Environmental Toxicology and Chemistry, vol. 23, pp. 271-282, 2004.

[10] L. Hakanson, "An ecological risk index for aquatic pollution control, a sediment-ecological approach," Water Research, vol. 14, pp. 975-1001, 1980

[11] C. W. Chen, C. F. Chen, and C. D. Dong, "Distribution and Accumulation of Mercury in Sediments of Kaohsiung River Mouth, Taiwan," APCBEES Procedia, vol. 1, pp. 153-158, 2012.

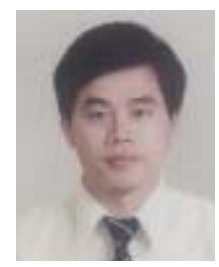

C. D. Dong was born in Kaohsiung, Taiwan. Date of Birth May 15, 1963. Educational Background: Ph.D. (Environmental Engineering). He got her Ph.D. degree in 1993 in the area of advanced oxidation process. He is working as a professor in Department of Marine Environmental Engineering, National Kaohsiung Marine University, Taiwan since August, 1992. Present position: Professor in NKMU Taiwan. Dong works in the area of Marine Environmental Engineering. He is having 57 numbers of journal Publications and 70 numbers of Conference publications.

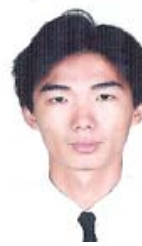

C. F. Chen was born in Kaohsiung, Taiwan. Date of Birth October 4, 1977. Educational Background: Ph.D. (Environmental Engineering). He got her Ph.D. degree in 2010 in the area of sediment contamination. $\mathrm{He}$ is working as an assistant research fellow in Department of Marine Environmental Engineering, National Kaohsiung Marine University, Taiwan since August, 2010. Chen works in the area of Marine Environmental Engineering. He is having 12 numbers of journal Publications and 22 numbers of Conference publications.

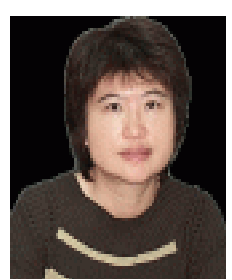

C. W. Chen was born in Kaohsiung, Taiwan. Date of Birth 1st October 1963. Educational Background: $\mathrm{Ph} . \mathrm{D}$. (Environmental Engineering). She got her Ph.D. degree in 2006 in the area of sediment metal contamination. She is working as a professor in Department of Marine Environmental Engineering, National Kaohsiung Marine University, Taiwan since August, 1992. Present position: Professor in NKMU Taiwan. Chen works in the area of Marine Environmental Engineering. She is having 56 numbers of journal Publications and 66 numbers of Conference publications. 